\title{
Perspectives of Pharmacy Graduates Toward an Undergraduate Ethics Course and Its Potential Impact on Their Professional Practice
}

This article was published in the following Dove Press journal:

Advances in Medical Education and Practice

\author{
Nadir Kheir (D) \\ Ahmed Awaisu (iD ${ }^{2}$ \\ Sohayla Ibrahim² \\ Sara Murshid Al-Dulaimi ${ }^{3}$ \\ Hoda Gad (iD 4 \\ 'College of Pharmacy, Ajman University, \\ Ajman, United Arab Emirates; ${ }^{2}$ College of \\ Pharmacy, Qatar University Health, \\ Doha, Qatar; ${ }^{3}$ Pharmacy Department, \\ Women Wellness and Research Center, \\ Hamad Medical Corporation, Doha, \\ Qatar; ${ }^{4}$ Department of Medicine, Weil \\ Cornell University, Doha, Qatar
}

Purpose: The aim of this study was to gauge the opinions and attitudes of pharmacy graduates toward an undergraduate ethics course they received and to explore if the ethics course was relevant to their practice.

Sample and Methods: This online questionnaire-based study involved pharmacy college graduates (alumni) who, at the time of the study, were practicing in different practice settings and who had all graduated from the same college of pharmacy in Qatar. An online questionnaire comprising 27 items related to attitudes, perceptions, and impact of the undergraduate ethics course on professional practice was distributed through email to all eligible alumni. Both descriptive and inferential statistics were performed for data analyses, with a p-value $<0.05$ considered statistically significant.

Results: Of 119 invited graduates, 62 (52.1\%) responded to the survey. About $73 \%$ of the respondents were satisfied with the ethics course received and $77.5 \%$ agreed that the course helped them in applying ethical principles in practice. Over $57 \%$ of the respondents discussed ethical issues in practice and $84.2 \%$ of these reported that the discussions were influenced by having had the ethics course. Barriers to applying ethical principles and discussing ethical issues in practice included lack of time (41\%) and lack of reliable resources $(23.1 \%)$. Participants' years of experience did not influence their attitudes toward the ethics course and its impact on professional practice ( $\mathrm{p}>0.05$ for both). However, practicing in a hospital setting or completing postgraduate education had a significant influence on the perception of the impact of the course on professional practice ( $\mathrm{p}=0.036$ and $\mathrm{p}=0.035$, respectively).

Conclusion: A large proportion of pharmacy graduates value the ethics course received during their undergraduate program in pharmacy. The course appeared to have a positive influence on graduates' professional practice. Future studies should investigate specific areas that need to be reinforced in the curriculum and reliable reference resources should be developed and/or identified.

Keywords: alumni, pharmacy education, ethics, professionalism

\section{Introduction}

Ethics is a system of moral principles that involves the application of values and judgments to human practices. ${ }^{1}$ Medical ethics was known since the times of Hippocrates and Galen, and throughout the middle ages until modern times. ${ }^{2}$ However, courses in medical ethics for undergraduate students have become part of the core curriculum in most medical schools in developed countries only in the early twentieth century, and medical ethics became an important part of formal

Correspondence: Nadir Kheir College of Pharmacy, Ajman University, Ajman, United Arab Emirates Tel +971509597589

Email a.kheir@ajman.ac.ae 
medical education only during the past three decades. ${ }^{3}$ The shift of the practice of pharmacy towards patient-centered care rather than merely filling and dispensing prescriptions challenged pharmacists to adopt higher levels of responsibilities and more involvement in the decision-making process involving patient care. ${ }^{4,5}$ Because of the new roles of pharmacists that brought them closer to patients and other healthcare practitioners, pharmacists started encountering complex ethical issues and dilemmas that require them to take decisions of ethical nature and be able to defend these decisions. $^{6}$

The significance of ethics in pharmacy practice had been recognized by several pharmaceutical and regulatory bodies, and this was reflected in professional competencies that a licensed pharmacist must meet at graduation. The National Association of Pharmacy Regulatory Authorities (NAPRA) in Canada, for instance, outlined ethical, legal, and professional responsibilities as one of the competencies that a pharmacist should meet at the point of licensure. ${ }^{7}$ Thus, developing requisite knowledge and skills in ethics as well as proficiency in resolving ethical dilemmas should be a fundamental part of the pharmacy curriculum. Ethics education started to emerge only in the past few decades in pharmacy curricula. ${ }^{8}$ While ethics courses have become a fundamental part of pharmacy education in the industrialized countries like the United Kingdom, the United States, and Canada, such courses are just emerging in many developing countries and are now being taught to pharmacy students as a single-unit course in a number of countries of the Middle East. ${ }^{8,9}$ Yet, the curriculum content and the teaching methods of such courses vary, and a need exists for evaluating the relevance and potential impact of these courses on professional pharmacy practice.

A core course, entitled "Pharmacy Law and Ethics", was introduced in the College of Pharmacy since 2009. The college is committed to continuous quality improvement of its curriculum to ensure program learning outcomes are being met and to comply with international accreditation standards. The Pharmacy Law and Ethics course achieves one of the program outcomes of the College (Professional Competencies and Educational Outcomes), where it was designed to comply with an adapted version of the 2006 Canadian Council for Accreditation of Pharmacy Programs (CCAPP) accreditation standards and guidelines for a baccalaureate degree program in pharmacy. ${ }^{7}$ The course also ties well with the stated Core Values of the College, which are Professionalism, Respect, Commitment, Impact, Innovation, and Partnership.

As a best practice, students and often graduates enrolled in courses are required to evaluate courses and provide feedback for the purpose of teaching and learning quality improvement. The goal of this paper is to report about the course development and implementation and the perspectives of the pharmacy graduates who took the course on its design, teaching pedagogies, content delivery, and impact on their current practice. The objectives of this study were to identify how a Pharmacy Law and Ethics course delivered to undergraduate students was perceived by graduates who took the course and how relevant to practice the course was. The study also aimed to gauge the graduates' opinions on the content, delivery methods, and barriers they face to practice what they learned.

\section{Materials and Methods Description of the Pharmacy Law and Ethics Course}

This Pharmacy Law and Ethics course (Table 1) is a onecredit hour course (one hour lecture every week for the 15week of the Spring Semester) and it focuses on ethical, legal, and cultural aspects of pharmacy practice and research. Overall, the course is intended to provide the student with the understanding of traditional and contemporary ethical terms and principles, drawing from national and international professional environments. The following set of learning outcomes guided the content of the course:

1. To articulate the importance of ethics and laws in protecting the human rights of individuals in the society.

2. To debate issues surrounding ethics, values, professionalism, culture, and social behavior as they relate to pharmacy and healthcare.

3. To explain the principles governing research ethics with reference to landmark human experiments that shaped health research.

4. To discuss healthcare ethics and ethical dilemmas and be able to make sound ethical decisions concerning patients based on principles of ethical decision-making.

5. To integrate ethical principles in model pharmacy practice environments.

The lectures address the following principles and topics: traditional ethical principles; contemporary ethics; 


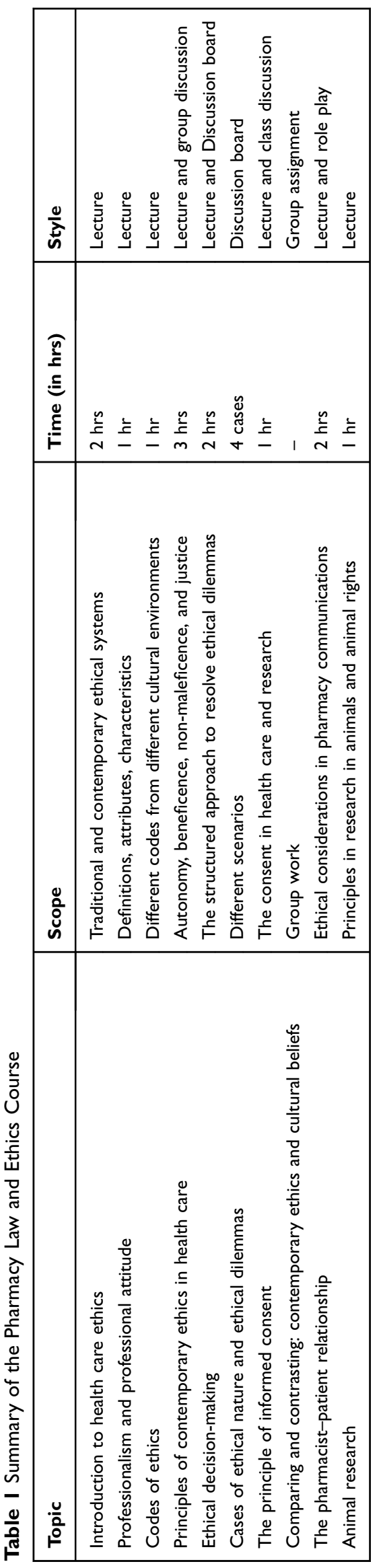

professionalism; codes of ethics; ethical decision-making; autonomy, veracity, and justice; principles of informed consent; the pharmacist-patient relationship; ethics committees; and animal research.

The course includes discussions and debate elements managed through a Discussion Board platform available in the College's online teaching and learning software (Black Board). Contribution in the Discussion Board is assigned $5 \%$ of the total course grade. Five questions or cases are posted by the course coordinator throughout the semester, and students are invited to contribute a minimum of 5 post per question or case. Grading of the posts is carried out using a rubric. Other assessment components of the course include a group assignment ( $10 \%$ of the course grade), one mid-term examination ( $30 \%$ of the course grade), classparticipation ( $10 \%$ of the course grade), and a final examination ( $45 \%$ of the course grade). Box 1 provides examples of a group assignment and a Discussion Board case.

\section{Study Design and Study Population}

An online cross-sectional questionnaire-based study was conducted from February to May 2017. The study population included all alumni of the college of pharmacy. At the point of survey distribution, a total of 123 students had graduated from the college since its inception. With the exclusion of four graduates; three being involved in the piloting process and one in conducting this study, the study population consisted of 119 graduates.

\section{Questionnaire Development}

The survey was developed through extensive literature search and thorough discussion among the researchers. ${ }^{10-13}$ A draft questionnaire was reviewed for content by two faculty members with expertise in questionnaire development, and then piloted on three graduates who were purposively sampled from the target population. Those graduates who piloted the questionnaire were excluded from the final sample. The final instrument included 27 items distributed in three domains. The first domain (six items) collected demographic information of the respondents (year of graduation, highest academic qualification, current setting, current position, duration in the current position, and whether they attended ethics-related training or professional development activities). The second domain (seven items) asked about attitude towards the course on a 5-point Likert scale (strongly agree, agree, neutral, strongly disagree, disagree) and an option where the respondent "cannot recall". The last domain generated data on the ethics course's relevance to practice: 
Box I Sample Assignment and Discussion Board Case

\begin{tabular}{|c|c|}
\hline Example of Group Assignment Topic & Example of A Discussion Board Case \\
\hline $\begin{array}{l}\text { In today's healthcare, an advanced knowledge about medical and } \\
\text { healthcare ethics (and ethical principles) help healthcare professionals to } \\
\text { adhere to high moral codes in their day-to-day dealings with patients. } \\
\text { However, ethics has roots deep in "culture", religion, and and societal } \\
\text { beliefs. In this assignment, you are required to compare and contrast } \\
\text { between contemporary ethical principles found in today's codes of } \\
\text { ethics or integrated in practice models and teachings, cultural } \\
\text { constructs, tribal beliefs, proverbs, or religious teachings originating } \\
\text { from societal standpoints. The ethical principle you should focus on are: } \\
\text { Consequentialism and Deontological theories. }\end{array}$ & $\begin{array}{l}\text { You have graduated as pharmacist, and your life took you overseas, } \\
\text { to live and work in the United Kingdom (UK). You passed the } \\
\text { requirements for registration as pharmacist in the UK, and you were } \\
\text { employed in this community pharmacy in the city. One morning, an } \\
\text { I8-year female came in the pharmacy asking to see the pharmacist. } \\
\text { She asked for the "morning-after pill". This is a contraceptive pill that } \\
\text { pharmacists are allowed to dispense without a prescription and to } \\
\text { counsel the patient on safety issues and method of administration. } \\
\text { The morning-after pill was specifically approved for the purpose of } \\
\text { preventing un-planned pregnancy after unprotected sexual } \\
\text { intercourse or when protection fails. } \\
\text { Would you dispense or not? Why would you take the action you are } \\
\text { proposing to take? In either case, discuss your chosen action and } \\
\text { point out to ethical issues supporting your action. }\end{array}$ \\
\hline
\end{tabular}

perception of the impact of the course on practice (five items) and application of ethics in practice (eight items). The items in the last domain (perceived impact on practice) were structured around ethical topics covered during the ethics course, mainly dealing with ethical dilemmas, ethics and the conduct of research, and problems of ethical and professional nature faced during practice (Table 1). Participants were finally asked for suggestions on how to improve the course (one open-ended question).

\section{Survey Administration}

Data were collected through a self-administered questionnaire using an online tool (Survey Monkey). A link to the questionnaire was emailed to eligible participants and a weekly reminder was sent thereafter.

\section{Statistical Analysis}

All data were analyzed using the Statistical Package for the Social Sciences (SPSS) version 24. Descriptive statistics, such as frequencies and percentages, were used to summarize questionnaire responses. Inferential analysis using Chi-square test was used to determine the influence of participant's educational and professional characteristics on certain attitudinal items. The level of statistical significance was set at $\mathrm{p}<0.05$.

\section{Ethical Consideration}

The study was approved by Qatar University's Institutional Review Board (IRB 741-E/17). Participants were informed about the voluntary and confidential nature of the study. All responses to the survey were kept strictly confidential and anonymous.

\section{Results}

Of the 119 alumni who were sent the online link to the survey, 62 alumni (52.1\%) completed the survey. Of the respondents, $30.65 \% \quad(\mathrm{n}=19)$ graduated with a BSc Pharm degree in 2016, while $8.06 \%(\mathrm{n}=5)$ graduated in 2011. More than half $(53.22 \%)$ of the participants were employed, while $25.81 \%$ were doing postgraduate studies (PharmD, MSc, or PhD). Details of participant's educational and professional characteristics are provided in Table 2.

\section{Attitudes of Pharmacy Graduates Toward the Ethics Course Studied}

A summary of the graduates' attitudes toward the ethics course and its delivery methods is presented in Table 3. $48 \%(n=30)$ of the respondents thought that one credit hour was adequate for covering relevant topics in ethics. Regarding the ethics course delivery methods, more than half of the respondents $(69.49 \%$, $\mathrm{n}=41$ ) agreed that the methods used for teaching were adequate, and $56.9 \%(n=33)$ thought that sharing opinions through the Discussion Board contributed to their learning. Nevertheless, $72.41 \%(n=42)$ agreed that the course needs to include more cases and $76.27 \%(n=45)$ believed that the course would benefit from invited contributions. Overall, $81.35 \%(n=48)$ believed that they have generally benefited from the ethics 
Table 2 Educational and Professional Characteristics

\begin{tabular}{|c|c|c|}
\hline \multirow[t]{2}{*}{ Variable } & Total & \multirow{2}{*}{$\begin{array}{l}\text { Frequency } \\
\text { (\%) }\end{array}$} \\
\hline & $(\mathrm{N}=62)$ & \\
\hline $\begin{array}{l}\text { Year of graduation with BSc Pharm degree } \\
2011 \\
2012 \\
2013 \\
2014 \\
2015 \\
2016\end{array}$ & 62 & $\begin{array}{l}5(8.06) \\
7(11.29) \\
10(16.13) \\
11(17.74) \\
10(16.13) \\
19(30.65)\end{array}$ \\
\hline $\begin{array}{l}\text { Highest academic qualification } \\
\text { BSc Pharm } \\
\text { PharmD } \\
\text { MSc } \\
\text { PhD } \\
\text { Others }\end{array}$ & 62 & $\begin{array}{l}34(54.84) \\
16(25.8 \mathrm{I}) \\
\mathrm{II}(\mathrm{I} 7.74) \\
\mathrm{I}(\mathrm{I} .6 \mathrm{I}) \\
0(0.00)\end{array}$ \\
\hline $\begin{array}{l}\text { Current setting/status** } \\
\text { Community pharmacy } \\
\text { Hospital pharmacy } \\
\text { Primary Health Care clinic } \\
\text { Research work (full time) } \\
\text { Postgraduate study } \\
\text { (e.g. PhD; PharmD) } \\
\text { Academia } \\
\text { Unemployed } \\
\text { Others }\end{array}$ & 62 & $\begin{array}{l}I(1.6 \mathrm{I}) \\
28(45.16) \\
0(0.00) \\
5(8.06) \\
16(25.8 \mathrm{I}) \\
3(4.84) \\
13(20.97) \\
3(4.84)\end{array}$ \\
\hline & $(\mathrm{N}=49)^{* *}$ & \\
\hline $\begin{array}{l}\text { Current position } \$ \\
\text { Pharmacist } \\
\text { Clinical pharmacist } \\
\text { Researcher (full time) } \\
\text { Postgraduate student } \\
\text { Academic staff } \\
\text { Others }\end{array}$ & 49 & $\begin{array}{l}14(28.57) \\
15(30.61) \\
4(8.16) \\
19(38.78) \\
0(0.00) \\
I(2.04)\end{array}$ \\
\hline $\begin{array}{l}\text { Duration in current position* } \\
<1 \text { year } \\
\text { I-2 years } \\
3-4 \text { years } \\
\geq 5 \text { years }\end{array}$ & 48 & $\begin{array}{l}21(43.75) \\
8(16.67) \\
18(37.50) \\
I(2.08)\end{array}$ \\
\hline $\begin{array}{l}\text { Have you ever attended (CPD) } \\
\text { sessions or courses related to ethics } \\
\text { and/or pharmacy laws, apart from the } \\
\text { ethics course learned in the College? } \\
\text { Yes } \\
\text { No }\end{array}$ & 49 & $20(40.82)$ \\
\hline
\end{tabular}

Notes: *Missing data. **Results reflect responses of currently practicing alumni. ${ }^{\$}$ This question allows for multiple responses.

course and $73.19 \%(n=42)$ were satisfied with the course (Table 2).

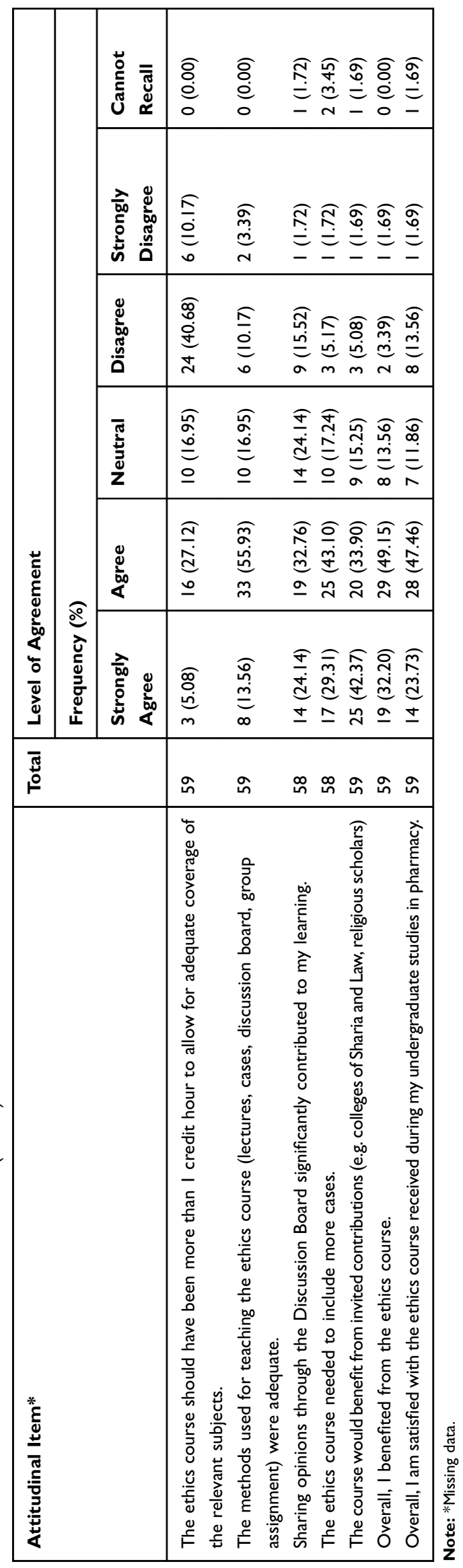




\section{Perceived Impact of the Ethics Course on Practice}

Out of the currently practicing graduates who responded to the survey (49), 40 answered this section. A large percentage of respondents $(77.5 \%, \mathrm{n}=31)$ agreed that the ethics course assisted them in applying ethical principles in practice. In addition, $77.5 \%(n=31)$ of the respondents believed that the course influenced the way they responded to ethical issues in practice, and $75 \%(n=30)$ of the respondents agreed that it allowed them to practice professionally. Over $72 \%(n=29)$ of the pharmacy graduates reported that the ethics course helped them deal with real-life ethical dilemmas, while $80 \% \quad(n=32)$ believed that it opened their eyes to ethical issues that otherwise would have passed unnoticed (Table 4).

\section{Application of Ethics in Practice}

Out of the currently practicing graduates who responded, 38 answered this section. The most commonly reported ethical principles applied in practice were; confidentiality (94.7\%), beneficence $(86.8 \%)$, patient's consent $(84.2 \%)$, non-maleficence $(81.6 \%)$, and patient's autonomy $(81.6 \%)$ (Table 5). The study results showed that over $57 \%$ of the respondents at least sometimes discuss ethical issues with others in their practices. The majority of the respondents $(84.21 \%)$ reported that the discussions were influenced by having had the ethics course in their undergraduate curriculum (Table 5).

As for reporting ethical concerns, only $10.53 \%$ of the respondents often report ethical concerns in their practice, while $26.32 \%$ of them never do so. When compared to discussing ethical issues, a lower percentage (44.74\%) reported that recording ethical concerns was influenced by the ethics course studied (Table 6).

The barriers that limit pharmacy graduates from discussing ethical issues in practice are represented in Figure 1. The most commonly reported barriers were: lack of time $(41 \%)$ and lack of reliable resources $(23.1 \%)$. Other barriers that respondents reported included: lack of supporting law, contrasting religious and cultural backgrounds, and resistance by patients or healthcare providers to discuss such issues.

The ethics resources that are available to the respondent graduates at their practice sites were also reported. Most respondents (45.95\%) reported the lack of ethics resources in practice. The most widely available resource was websites from the Internet $(40.54 \%)$, followed by lecture notes $(21.62 \%)$. When asked about the ethics

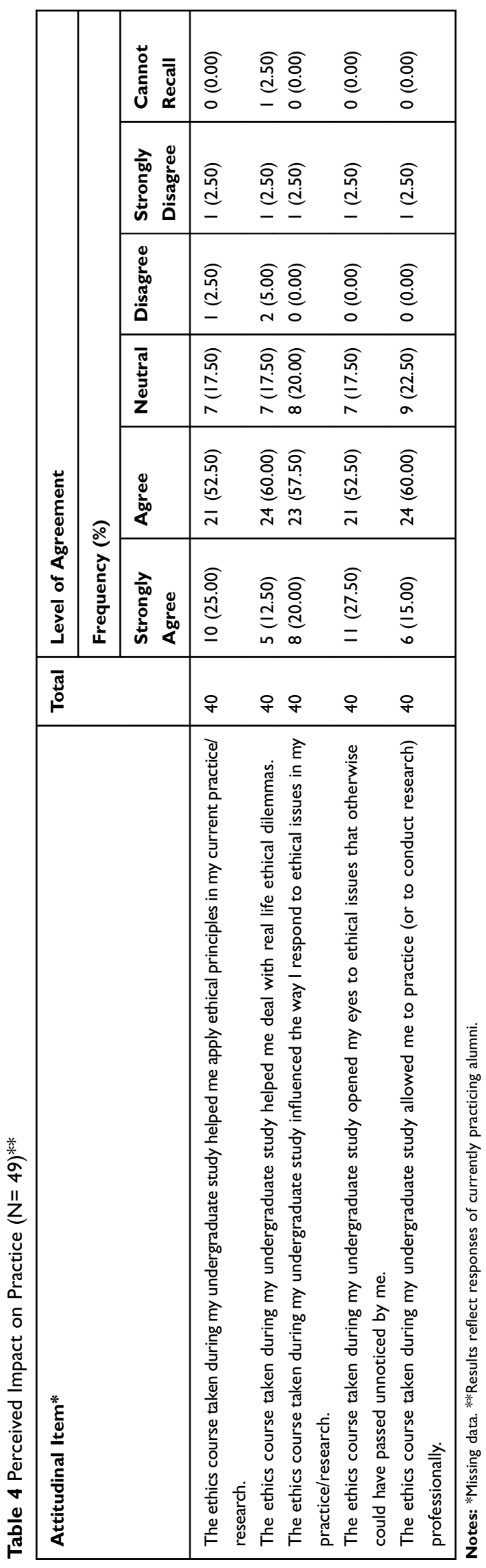


Table 5 Discussion of Ethical Issues During Practice $(\mathrm{N}=49)^{* *}$

\begin{tabular}{|c|c|c|}
\hline Survey Item* & Total & $\begin{array}{l}\text { Frequency } \\
\text { (\%) }\end{array}$ \\
\hline $\begin{array}{l}\text { How often do you discuss ethical issues with } \\
\text { your patients/clients/colleagues? } \\
\text { Never } \\
\text { Rarely } \\
\text { Sometimes } \\
\text { Often } \\
\text { Very often }\end{array}$ & 38 & $\begin{array}{l}0(0.00) \\
5(13.16) \\
22(57.89) \\
5(13.16) \\
6(15.79)\end{array}$ \\
\hline $\begin{array}{l}\text { Was your discussion of ethical issues } \\
\text { influenced by having had the ethics course in } \\
\text { your BSc Pharm curriculum? } \\
\text { I never discuss ethical issues with my } \\
\text { patients or colleagues } \\
\text { Yes } \\
\text { No }\end{array}$ & 38 & $\begin{array}{l}0(0.00) \\
32(84.21) \\
6(15.79)\end{array}$ \\
\hline
\end{tabular}

Notes: *Missing data. **Results reflect responses of currently practicing alumni.

Table 6 Reporting of Ethical Issues During Practice $(\mathrm{N}=49)^{* *}$

\begin{tabular}{|l|l|l|}
\hline Survey Item* & Total & $\begin{array}{l}\text { Frequency } \\
\text { (\%) }\end{array}$ \\
\hline $\begin{array}{l}\text { How often do you record or report ethical } \\
\text { concerns in your practice? } \\
\text { Never }\end{array}$ & 38 & \\
Rarely & & $10(26.32)$ \\
Sometimes & $11(28.95)$ \\
Often & $12(31.58)$ \\
Very often & $4(10.53)$ \\
\hline $\begin{array}{l}\text { Was reporting of (or documenting) ethical } \\
\text { issues during practice a result of having had } \\
\text { ethics course in your BSc Pharm curriculum? } \\
\text { I never reported/recorded ethical }\end{array}$ & 38 & $12.63)$ \\
concerns in my practice & & $12(31.58)$ \\
Yes & & $17(44.74)$ \\
No & & $9(23.68)$ \\
\hline
\end{tabular}

Notes: *Missing data. **Results reflect responses of currently practicing alumni.

resources that would be helpful in practice, the majority of the respondents $(70.27 \%)$ chose Internet websites and computer databases $(62.16 \%)$.

\section{Influence of Participant's Educational and Professional Characteristics on Attitudes Towards the Course and Its Impact on Practice}

The influence of the year of graduation, current practice setting, and whether participants attended continuing

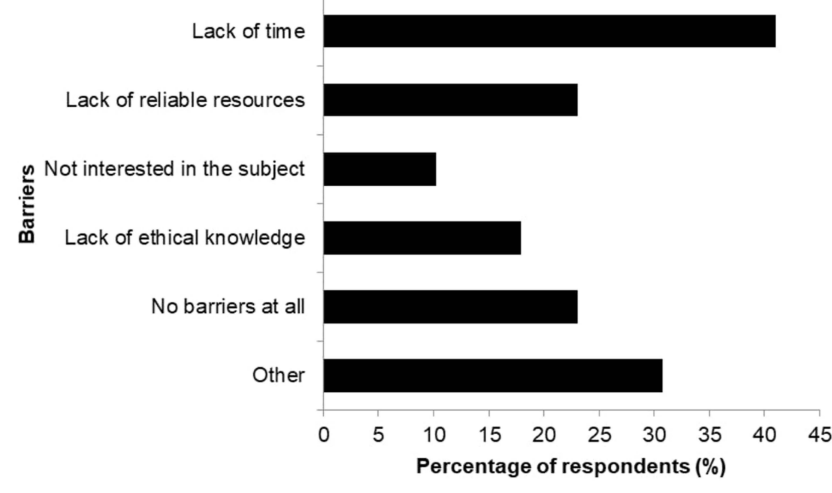

Figure I Barriers of addressing ethical issue $(\mathrm{N}=39)$. This question allows for multiple responses. Results reflect responses of currently practicing alumni.

professional development (CPD) courses on attitude towards the ethics course (attitudes towards the course and perceived impact of the course on practice) were assessed. Participant's year of graduation did not influence their level of agreement with both attitudinal items: overall satisfaction towards the course ( $\mathrm{p}$-value $=0.51)$ and perceived impact of the course on practice ( $p$-value $=0.458$ ).

Moreover, the practice setting showed no significant impact on the level of satisfaction towards the ethics course (p-value $>0.05$ for all practice setting). However, working in a hospital and having done postgraduate studies demonstrated a significant influence on the level of agreement with the attitudinal item of perceived impact on practice ( $p$-value $=$ 0.036 and $p$-value $=0.035$, respectively). Whether participants attended CPD courses or not demonstrated no influence on their level of agreement with both attitudinal items: overall satisfaction towards the course $(\mathrm{p}$-value $=0.750)$ and perceived impact of the course on practice $(\mathrm{p}$-value $=0.844)$.

\section{Feedback on How to Improve the Course} With Consideration to Realities of Practice

In examining the open-ended results, one respondent recommended involving the alumni to share few of the scenarios commonly encountered in practice that require ethical decision-making. Three participants suggested adding more cases to the course. In particular, one suggested including more cases with regard to professional relationships between pharmacists and one recommended adding more cases relating to pharmaceutical drug companies or natural product laboratories. In addition, one respondent recommended having more interactive learning techniques such as debates. Moreover, a participant suggested adjusting the course more to reflect the cultural constructs of the country. 


\section{Discussion}

Most of the graduates who participated in this study had positive attitudes towards the ethics course they received during their undergraduate studies and its delivery methods; and they perceived the impact of this ethics course on their practice to be of relevance. The majority of the participants were working in hospital pharmacy services or enrolled in postgraduate programs when the study was conducted. This might have had an influence on the overall response since in those settings, pharmacists get exposed to ethical issues more than other settings.

When evaluating attitudes towards the ethics course, graduates were generally satisfied with the course and its teaching methods. Nevertheless, some suggestions were made to enhance the content and delivery methods of the course. The majority of participants agreed that the course would benefit from invited contributions of the colleges of Law and sharia. This was consistent with a previous study which showed that students thoroughly enjoyed mock trials that included both pharmacy and law students. This mock trial helped them identify the complex relationships between healthcare ethics and law. ${ }^{14}$ Moreover, many participants suggested including more cases to the course from diverse backgrounds, for example to have cases on ethics related to pharmaceutical companies and professional conflicts rather than merely patients' cases. Teaching ethics in pharmacy using case-based discussions is a well-established method since $1997 .{ }^{15}$ It has shown to offer the possibility of engaging students in ethical reflections. Ethics-related group discussions enabled students to identify ethical problems, consider all options available, and justify their choice. Those skills collectively help students develop better ethical reasoning which would be reflected on their future practice. Moreover, a study conducted by Spies found that students appreciated the use of real cases and that the addition of "break-out" sessions made a positive impact on students. ${ }^{16}$ Others suggested including debate as a teaching method. This teaching method for ethical issues in pharmacy has been implemented and evaluated by Hanna et al and they concluded that debates effectively delivered the course content and resulted in enhancement of skills including team work, communication, and critical evaluation. ${ }^{1}$

With regard to the perceived impact of the course on practice, most practicing participants indicated that the ethics course received during their undergraduate studies was of relevance to their practice. Participants agreed that the course has helped them apply ethical principles, deal with ethical dilemmas, and practice professionally. It also influenced the way they respond to ethical dilemmas and made them more vigilant towards ethical issues. Those findings correlate well with the findings of a study that reported the impact of ethics education on moral actions of practicing nurses and social workers. Their data have shown that education and training in ethics had a significant influence on the confidence, use of ethics resources, and moral actions of social workers and nurses in practice. ${ }^{17} \mathrm{In}$ particular, participants practicing at hospital pharmacies or continuing post graduate studies have proven a significant effect of their current settings on their level of agreement to the attitudinal item of the perceived application of the course on practice. This significance is justifiable since participants in those two settings might be exposed to ethical issues to a higher extent than others. Also, a higher proportion of participants were practicing in those two settings which might derive the significance for only those settings.

Regarding the application of the ethics course on practice, our study found that confidentiality was the most ethical principle used in practice by pharmacists followed by beneficence, non-maleficence, and patient's autonomy. This correlates well with a previous study that found that patient's autonomy and non-maleficence were the primary bioethical principles applied by pharmacy students; however, practicing pharmacists also applied pharmacist's autonomy frequently. ${ }^{18}$ It is important to note that confidentiality was not part of the ethical principles assessed in that study and that in our study we did not include pharmacist's autonomy as a bioethical principle. Only recently, pharmacists have started enrolling in services and responsibilities that necessitate the use of beneficence as an ethical principle such as optimization of regimens or adherence support, rather than utilizing non-maleficence - through being a clinical checker - as a primary ethical principle. ${ }^{19}$

Most participants indicated that they sometimes discuss ethical issues with their patients, clients, or colleagues. Interestingly, none of them reported that they "never" discuss ethical issues. In most cases, participants indicated that their discussion was influenced by having had the ethics course during their undergraduate studies. When asked about barriers of discussing ethical issues, lack of time accounted for the highest percentage followed by lack of ethical resources and no barriers at all. Similar findings were shown by a study conducted on community pharmacists in Saudi Arabia, where lack of time was also the barrier perceived the most limiting to ethical discussions 
followed by lack of reliable resources. ${ }^{20}$ On the other hand, many participants indicated that they rarely or never report ethical concerns. However, among those who report or document ethical issues, higher proportion indicated that this reporting was influenced by having had the ethics course. This finding indicates that further attention is warranted towards the importance of reporting of ethical issues as part of the ethics course delivered.

As with the availability of ethics resources, surprisingly, the majority of participants indicated that no ethics references are available at their practice settings. However, a high proportion also indicated that internet websites were accessible as ethics references. When asked about the ethics resources that would be helpful to have in their practice, most of them indicated that internet websites and computer databases are useful formats of resources to have at their practice settings. Similar findings were assessed in a previous study that included only community pharmacists; however, in that study; pharmacists utilized books as their primary references followed by websites. They also perceived books and websites to be the most useful. ${ }^{20}$ This difference might be justified by the practice setting since in our study we had only one community pharmacist while in that study, all participants were community pharmacists. Collectively, those findings point to the importance of advocating the availability and utilization of ethics resources in different practice settings as part of the pharmacy references and to guide students on what ethics references to refer back when needed.

Our study has some important limitations. First, our response rate was not as high as we would have liked it to be. We tried to increase the response as much as possible by sending weekly reminders and by supplementing emails with a WhatsApp message to avoid failure of receipt of emails; yet, we did not achieve the response rate we aimed at possibly due to outdated email database. Second, some postgraduate participants might have misinterpreted the term "unemployed (not practicing, doing graduate studies, or in research)" which led them not to respond to the preceding sections, and subsequently there were fewer responses for these questions than anticipated. Moreover, some participants have received CPD sessions or ethics-related courses during their postgraduate studies which might have been a confounder. To overcome this, we deliberately included detailed information related to the course content and we emphasized that responses should reflect the ethics course specifically. We also analyzed the effect of ethics-related CPD attendance on different attitudinal items; however, no significant impact was noted. Finally, response bias is inherently associated with all surveys since respondents might consciously or subconsciously provide responses that they think the interviewer wants to hear. This type of bias could be minimized by emphasizing the anonymous nature of the questionnaire (which in our case was helped by utilizing an online survey).

\section{Conclusion}

In conclusion, the findings of this study showed that most participants value the ethics course and perceive a positive impact of the undergraduate ethics course on professional practice. Graduates generally demonstrated good application of the ethics course in practice. In addition, most practicing graduates who discuss ethical issues reported that the discussion was influenced by having had the ethics course in their undergraduate program. Top barriers that limit graduates from discussing ethical issues as reported by participants include lack of time and lack of reliable resources. Those findings project the importance of incorporating ethics courses in undergraduate pharmacy curriculum. The generalizability of the study findings remains challenged since it is one country study and by the relatively low response rate achieved. Therefore, one should interpret the findings with caution when applying to other educational settings or countries.

\section{Disclosure}

The authors report no conflicts of interest in this work.

\section{References}

1. Hanna L-A, Barry J, Donnelly R, et al. Using debate to teach pharmacy students about ethical issues. Am J Pharm Educ. 2014;78(3):57. doi:10.5688/ajpe 78357

2. Bjelica A. A short journey through the history of medical ethics. Med Pregl. 2017;70(3/4):119-122. doi:10.2298/MPNS1704119B

3. Al-Haqwi AI, Al-Shehri AM. Medical students' evaluation of their exposure to the teaching of ethics. J Fam Comm Med. 2010;17 (1):41-45. doi:10.4103/1319-1683.68788

4. Sharif PS, Javadi M, Asghari F. Pharmacy ethics: evaluation pharmacists' ethical attitude. J Med Ethics Hist Med. 2011;4:5.

5. Saw PS, Chuah LH, Lee SWH. A practical approach toward teaching ethics to community pharmacists. Int J Clin Pharm. 2018;40 (5):1131-1136. doi:10.1007/s11096-018-0707-8

6. Salari P, Abdollahi M. Ethics in pharmacy curriculum for undergraduate pharmacy students: a needs assessment study. Arch Iran Med. 2017;20(1):38-42

7. Professional competencies for Canadian pharmacists at entry to practice: National Association of Pharmacy Regulatory Authorities (NAPRA); 2014. Available from: http://napra.ca/content_files/files/ comp_for_cdn_pharmacists_at_entrytopractice_march2014_b.pdf.

8. Fawzi MM. Medical ethics educational improvement, is it needed or not? Survey for the assessment of the needed form, methods and topics of medical ethics teaching course amongst the final years medical students Faculty of Medicine Ain Shams University (ASU), Cairo, Egypt 2010. J Forensic Legal Med. 2011;18(5):204-207. 
9. Al-Aqeel SA. Pharmacy students feedback on the use of role-play in teaching ethics. Pharm Educ. 2013;13(1):140-144.

10. Boynton PM, Greenhalgh T. Selecting, designing, and developing your questionnaire. BMJ. 2004;328(7451):1312-1315. doi:10.1136/ bmj.328.7451.1312

11. Peeters MJ, Vaidya VA. A mixed-methods analysis in assessing students' professional development by applying an assessment for learning approach. Am J Pharm Educ. 2016;80(5):77. doi:10.5688/ ajpe 80577

12. Hasan S. Teaching ethics to pharmacy students using a team-based learning approach. Pharm Educ. 2015;11.

13. Vukovic Rodriguez J, Juricic Z. Perceptions and attitudes of community pharmacists toward professional ethics and ethical dilemmas in the workplace. Res Social Adm Pharm. 2018;14(5):441-450. doi:10.1016/j.sapharm.2017.05.010.

14. Broeseker AE, Jones MM. An interdisciplinary mock trial involving pharmacy, law, and ethics. Ann Pharmacother. 1999;33(7-8):850-858. doi:10.1345/aph.18355
15. Weinstein B. Teaching pharmacy ethics: the case study approach. J Pharm Teach. 1997;6(1-2):19-31. doi:10.1300/J060v06n01_02

16. Spies AR. Plaintiff or defendant: using legal cases to teach students pharmacy law. Am J Pharm Educ. 2008;72(5):108. doi:10.5688/ aj7205108

17. Grady C, Danis M, Soeken KL, et al. Does ethics education influence the moral action of practicing nurses and social workers? $\mathrm{Am} \mathrm{J}$ Bioeth. 2008;8(4):4-11. doi:10.1080/15265160802166017

18. Schlesselman LS. A cross-sectional study of applied bioethical reasoning in pharmacy students and preceptors. Pharm Prac (Granada). 2014;12(2):401.

19. Duffull SB, Wright DFB, Marra CA, Anakin MG. A philosophical framework for pharmacy in the 21 st century guided by ethical principles. Res Social Adm Pharm. 2018;14(3):309-316. doi:10.1016/j.sapharm.2017.04.049.

20. Al-Arifi MN. Community pharmacist perception and attitude toward ethical issues at community pharmacy setting in central Saudi Arabia. Saudi Pharm J. 2014;22(4):315-325. doi:10.1016/j.jsps.2013.08.003
Advances in Medical Education and Practice

\section{Publish your work in this journal}

Advances in Medical Education and Practice is an international, peerreviewed, open access journal that aims to present and publish research on Medical Education covering medical, dental, nursing and allied health care professional education. The journal covers undergraduate education, postgraduate training and continuing medical education

\section{Dovepress}

including emerging trends and innovative models linking education, research, and health care services. The manuscript management system is completely online and includes a very quick and fair peer-review system. Visit http://www.dovepress.com/testimonials.php to read real quotes from published authors. 